\title{
ACCOUNTABILITY PRESSURE AS DEBIASER FOR CONFIRMATION BIAS IN INFORMATION SEARCH AND TAX CONSULTANT'S RECOMMENDATIONS
}

\author{
Fauzan Misra $^{*}$, Slamet Sugiri ${ }^{2}$, Eko Suwardi $^{3}$, Ertambang Nahartyo $^{4}$ \\ ${ }^{1}$ Department of Accounting, Faculty of Economics, Andalas University, \\ Sumatera Barat, 25163, Indonesia \\ ${ }^{2,3,4}$ Department of Accounting, Faculty of Economics and Business, Universitas Gadjah Mada, \\ Yogyakarta, 55281, Indonesia
}

\begin{abstract}
Introduction: This study examines the influence of accountability pressure toward information search behavior and the subsequent tax recommendation. Background problem: Prior research has shown that tax consultants are subject to confirmation bias during their information search when providing recommendations to their clients. Nevertheless, less attention has been given to identifying boundary condition or mitigating factors. This study proposes accountability pressure to mitigate such bias. Novelty: This study broadens the understanding of the effect of different accountability pressures on an individual's effort and judgement making. Research Method: The research was conducted by an experimental approach using a 1x2 between-subjects design using an Internet-based instrument. Accountability pressure is manipulated into 2 levels (strong or weak). The experiment involved 82 tax professionals. Findings: The results show that accountability pressures influence the depth of the consultant information search. That is, a tax consultant those faced a high accountability pressure performed a deep search, while those who faced a weak accountability pressure conducted a shallow search. Then, a deep search leads to more conservative recommendations, while a shallow search leads to an aggressive recommendation. Furthermore, the results of interaction and simple effect tests show that the information search depth can mitigate confirmation bias occurred during information search processes. Conclusion: These findings imply that accountability within the organization needs to get more attention from tax consultants. While any prior research found that confirmation bias was proofed to have pervasive character and hard to be eliminated, this study pointed out that the accountability pressure could mitigate such bias.
\end{abstract}

ARTICLE INFO

\footnotetext{
* Corresponding Author at Department of Accounting, Faculty of Economics, Andalas University, Indonesia. E-mail address: fauzan_maestro@yahoo.com (author\#1), slamet.sugiri@ugm.ac.id (author\#2), e.suwardi@ugm.ac.id (author\#3),nahartyo@ugm.ac.id (author\#4)
} 


\section{INTRODUCTION}

A tax consultant has two roles in a taxation system, which areas the agent of the government (enforcer) and the advocate for the client (exploiter) (Klepper et al., 1991). A tax professional is a decision maker who is goaloriented, with the aim of maintaining the client's preference (Cuccia and McGill, 1990) while assisting to structurize the client's transactions in a consistent matter at the client's request (Klepper and Nagin, 1989). This advocating role makes judgments on tax decisions separate from other accounting domains, especially auditing (Roberts, 1998). Regarding to this role, American Institute of Certified Public Aaccountants (1995, 2008) suggests that the advocation role should not ignore objectivity in an information search and evaluation.

Professional standards do not prohibit a tax consultant from acting, based on the clients' interest,as long as there are proper supports for such a position. In fact, a tax consultant is viewed more as the client's advocate and can interpret the law in the best interests of the client (AICPA, 1995, 2008). Ayers et al., (1989) found that the tax consultants are more pro-taxpayers in their judgment when faced with ambiguous transactions. This bias could inhibit their ability to find the information objectively and subsequently lead to them making a biased decision (Bobek, Hageman and Hatfield, 2010; Kadous et al., 2008). A biased weighing of the evidence by tax professionals can unconsciously lead them to make a suboptimal decision (Kahle and White, 2004) and provide an improper tax recommendation (overaggressive) (Johnson, 1993; Cloyd and Spilker, 1999). The tendency of decision makers to prefer and to weigh as more important, and assess as more relevant the information that supports their initial belief or the desired conclusion,is known as "confirmation bias" (Nisbett and Ross, 1980). Andre (2008) states that tax consultants are not immune to this bias. This condition potentially exposes the clients and the tax professionals to some sanctions from the government, or might lead to damaging their professional reputation (Cloyd and Spilker, 1999; Kadous et al., 2008).

Considering the potential risk of the confirmation bias, it is important to pay attention to mitigate such bias. Some prior researchers have offered various mechanisms for confirmation bias's mitigation, such as the group process (Schulz-Hardt et al., 2000), decision maker experiences (Jones and Sugden, 2001) and the use of judgment aids (Wheeler and Arunachalam, 2008), however, not all those mechanisms seemed effective. The one thing that had been forgotten by the priorresearchers was the bias identification type and how the bias can occur. Kennedy (1993) classified bias into two categories, whichare data-related bias and effort-related bias. The confirmatory bias is included in the effort-related bias; therefore the mitigation mechanism that induces the effort (effort-inducing) might be more effective. Accountability pressure is considered to be an effort-inducing mechanism.Accountability pressure is the pressure perceived by individuals to fulfill the requirements requested by the source of the accountability (the party to whom they are accountable) for the work assigned to them. Hence, this research proposesaccountability pressure as a bias mitigation mechanism

Ditto and Lopez (1992) and Ditto et al. (2003) suggest that the effect of directional preference toward the behavior should consider how the information is searched for and processed. Therefore, to get a deeper insight about how information search behavior influences tax recommendations, it is important to do some research about the factors which affect information search behavior, and their subsequent effect on tax recommendations. 
Although there are already several studies on the information search by tax professionals (Such as Cloyd and Spilker, 1999; Kadous et al., 2008), these studies only focus on the type of information search and ignore the depth of the information search. Solely focusingon the information search type restricts the understanding of the nature of any bias that may be incurred during the information search process. This research wants to broaden the prior research by testing both information search categories and their impact on tax recommendations. This research aims to investigate the effect of accountability pressure on the information search depth and it's effectiveness to mitigate the confirmation bias found in Misra et al., (2018a). Specifically, the objectives of this research are (1) to examine the effect of accountability pressure on the information search depth, and on the subsequent tax recommendation provided, and (2) to examine the interaction effect and the simple effect between the information search type and information search depthon the tax consultant's recommendation, to describe how accountability pressure could mitigate the confirmation bias.

This paper contributes to the existing literature in several ways. Firstly, this study broadens the understanding of the effect of different accountability pressures on anindividual's effort and judgment making. Second, this research shows how a debiaser can mitigate a confirmation bias in the information search and evaluation processes. Finally, for the tax consultants'office, this study provides a deeper insight concerning fulfilling the supervision requirements which are stipulated into the codes of ethics and the Professional Standards of Tax Consultants. With this, it will encourage tax consultants to balance their role as client advocates and government agents in a better way. For the government and the tax consultants association, this research will be beneficial as an input to the policymakers, particularly when related to the supervision and monitoring in a tax consultant's office.

The paper follows with a literature review and hypothesis development, method, results, and discussion.

\section{LITERATURE REVIEW AND HYPOTHESIS DEVELOPMENT}

\section{The Role of a Tax Consultant and Confirmatory Behavior}

Among the various advisory services offered by accounting firm, the tax consultancy service has become one of the most important components. This service requires a high quality advice from tax professional (Andre, 2008). Furthermore, when a client needs advice, the tax consultant may face the possible situation of there being some uncertainty about the correct action for the client's transaction. When facing this uncertainty, a tax consultant has to conduct research into the tax regulations, and if any cases have appeared previously in the tax court related to the client's problems, until a solution is reached (Marshall et al., 1992). Considering the massive amount of cases on certain issues, and the limitation of time, Wheeler and Arunachalam (2008) suggest that a researcher consultant has to be selective in choosing the authoritative evidence which will be read and used as a consideration in making a judgment

Findings from the psychological research show that individuals tend to exhibit a bias when making a judgment and decision, or when verifying an assumption. With this bias, people tend to limit their attention to the preferred hypothesis, and tend to choose evidence or information which supports their beliefs. Thus, they search mostly in the positive cases, give more weight to confirmatory cases, and tend to interpret information in ways that increase their 
confidence in favored hypothesis (Nickerson, 1998). Wason (1960) and Nisbett and Ross (1980) explain this situation as "confirmation bias".

Consistent with findings in the psychology and other accountingdomains (especially in auditing), research about tax professionals has also found confirmatory bias in several tax settings. The previous researchers such as Johnson (1993), Cloyd and Spilker (1999), Kadous et al.(2008) and Cloyd et al. (2012) found that duringresearch into a client's issues, tax professionals tend to focus their search on the positive cases anddiscount the negative ones, even to the point of improper aggressiveness. A positive case is a case that leads to a consistent conclusion for the client's tax position, while a negative one is a case which leads to an opposite conclusion to the preferred tax position suggested by the client. As suggested by Kadous et al. (2008), confirmation bias might cause a suboptimal judgment and expose the client and tax consultant to several risks, such as sanctions from those in authority and damage to their professional reputation. Therefore, the bias should be mitigated.

\section{Accountability Pressure}

Lerner and Tetlock (1999) define accountability as individual expectation, and that they probably will be asked to justify their behavior to the audience. A similar definition is provided by Turner (2001), who defines accountability as an obligation to justify someone's position in front of someone important. DeZoort et al. (2006) present two theoretical perspectives to explain why accountability pressure influences the judgment of the decision maker. First, Schlenker and Leary (1982) discuss the social anxiety created when accountability pressure appears. They conceptualize the accountability-based anxiety using a model of "self-attention" from
Carver (1979), in this case, self-attention raises a concern about the standard perception of behavior. Second, Tetlock (1992) proposed the social contingencies model which implies that accountability pressure may stimulate the need for political motivationto maintain a positive imagefor the important evaluative constituent.

Gibbins and Newton (1994) implied that there are three parts to the process of psychological mechanisms behind accountability pressure. First, individuals must be aware of this pressure. Second, awareness must direct the individuals to get approval or to avoid sanctions. Last, an individual must become involved in cognitive strategies to achieve their goals.

The prior literature also considers that accountability is a complex construction with several different levels, which has the power to influence a person's judgment and decision making. Lerner and Tetlock (1999) show the need for these researchers to consider the empirical differences among some types of accountability, which are(1) the attendance of someone else (i.e, a participant expecting to observe a performance, (2) identifiability (i.e, the participant expecting any follow-up dealing with their performance achievements), (3) reason-giving (participant can be expected to justify their actions toward other people), and (4) evaluation (participant expected that there are several asssesments in measuring the performance). DeZoort et al. (2006) classify the first two types as weak accountability pressure and the rest of the types as strong accountability pressure.

\section{Hypothesis Development}

Figure 1 below is the research framework for the development of the hypotheses. This research focuses on examining the role of the accountability mechanism to mitigate the confirmation bias as shown by Misra et al. (2018a). 


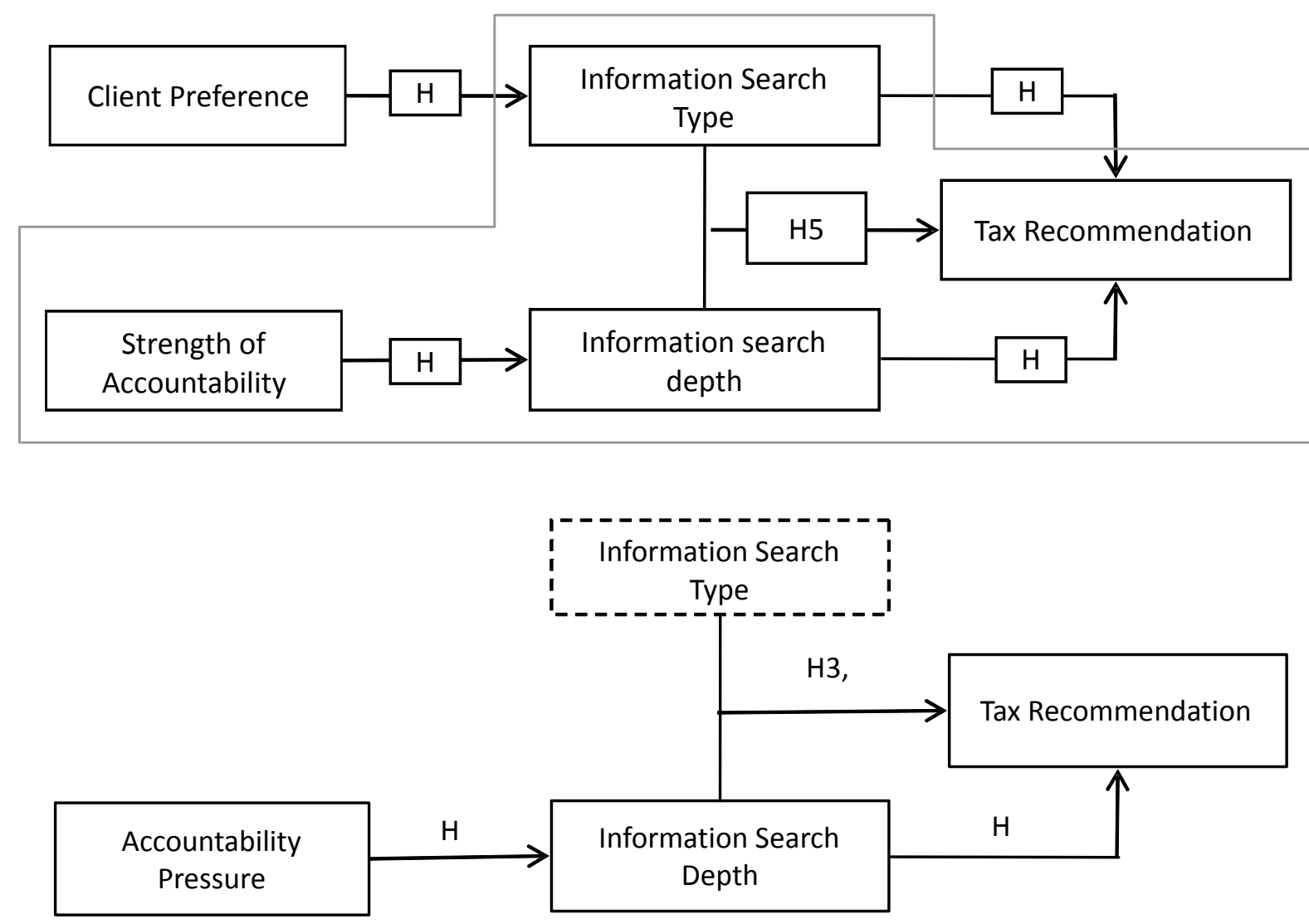

Figure 1. Research Framework

\section{Accountability Pressure Strength and Information Search Depth}

Gibbins and Newton (1994) state that there are three psychological mechanisms behind the accountability pressure, that is, the individual has to recognize the existence of the pressure, then, the recognition leads the individual to get the approval, or avoid the sanction, and the individual will be committed to acognitive strategy to reach her/his purpose. Gibbins and Newton's(1994) explanation is relevant to define accountability in the working environment of tax consultants due tovarious reasons. First, the tax consultant's staff recognize the accountability pressure from their supervisor. Second, the consultant pays attention to the sanctions which may be issued by the government if his/her performance is not in accord with the applicable regulations. Meanwhile, the consultant's staff pay attention to the need to get approval from their supervisor for the result of their work. The last one, based on Tetlock (1985) refers to someone who is under accountability pressure, and will make any effort to achieve their objectives.

Tetlock et al. (1989) states that one of the ways to answer the accountability demand is to let more cognitive effort out, such as thinking accurately about the alternatives or using a deeper and more detail analytical technique. DeZoort et al. (2006) state that in an ambiguoussetting, any increment in accountability pressure willincreaseawareness, and motivate the auditor to make a positive impression on the evaluative audience. Hoffman and Patton (1997) found that justification pressure leads to a more conservative risk and fraud evaluation.

Psychological research implies that accountability pressure can motivate someone to use more cognitive effort (Tetlock 1983). This is 
part of the result of someone's attention toward the personal consequences. Simonson and Staw (1992) state that an individual, in an accountability condition, will increase their cognitive effort and involve themselves in a more comprehensive processing of the information. Individuals in the accountability environment also shown more attention to self-criticism and carefully analyze all the relevant information which is available to them (Lerner and Tetlock, 1999). In general, the accountability literature implies that an accountable subject leads to more effort than the non-accountable subjects put out. For example, DeZoort et al. (2006) found that astronger accountability pressure positively related to the time spent to conduct a task, to making a longer explanation of their judgment, and to consideringqualitative materiality factors. Cloyd (1997) found that the feedback pressure increased the amount of time spent by tax professionals searching and evaluating information in their tax research assignments. The findings of the accountability effect toward the information search depth are also shown by Olvera (2012), Chen et al. (1996), and Raush and Brauneis (2015).

The explanation and findings imply that when the staff conduct a search for information under accountability pressure from their supervisor, they will be involved at a different effort level, which in this research is referred to as the informationsearch depth. Therefore, it could be predicted that staff under stronger accountability pressure will be involved in a deeper search, while the staff underweak accountability pressure will undertakea shallow search. The information search depth is manifested by the duration spent reviewing all the provided information and the information items used as guidance in providing a recommendation. This explanation leads to Hypothesis 1 (H1) below:
H1: Tax consultant staff who receive strong accountability pressure will spend more time and save more information items,rather than those who receiveweak accountability pressure.

\section{Information Search Depth and Tax Recommendation}

The previous research (i.e DeZoort et al., 2006; Kennedy,1993; Ashton, 1992; Cloyd, 1997) have shown the effect of accountability pressure on performance. DeZoort et al. (2006) found that when accountability pressure increases, an auditor will exert more effort into making a materiality judgment, which results in a more conservative judgment and a lower variability in the judgment. Other studies show that accountability pressure decreases the auditors' judgment bias (Kennedy, 1993) and increases the auditors' judgment accuracy (Ashton,1992). Cloyd (1997) argues that once more effort is expended on a case, a more productive searching strategy will be found, and as consequence, it will enable someone to identify the relevant information more easily. The result of his study supports the argument by finding out that anincrease in the effort's duration, which can be attributed to accountability manipulation, increases the effectiveness of the information search process.

The first hypothesis states that the tax consultant staff under a higher accountability pressure condition,will search for more information rather than the tax consultant under a lower accountability pressure condition. This assertion can be broadly based on the findings of prior research (such as by Olvera, 2012; Cloyd et al., 2012), in this case, a tax consultant using a deeper information search will acquire more information, both supporting and opposingthe client's preferences. This condition will lead the tax consultant to make a more careful and 
conservative recommendation. However, the consultant who is involved in a shallow information search has less information to make a judgment, and most of it isinformationthat is consistent with the client's preference. This situation subsequently leads them to suggest a more aggressive tax recommendation. It means that the depth of the information search influences the tax professional's recommendations. This explanation leads to Hypothesis 2 (H2) as follows:

H2: The longer the search duration and the greater the number of items saved by staff during the information search process are negatively related to the tax recommendation.

\section{Information Search Type, Information Search Depth, and Tax Consultant's Recommendations}

To gain a deeper understanding about how directional preferences affect the exhibited behavior, it is necessary to consider how information is searched for and processed (Ditto and Lopez, 1992; Ditto et al., 2003). Hales (2007) states that an understanding of the basic determinants of information processing helps to provide a better understanding about what kind of conditions might trigger a judgmental bias, and what conditions make it worse or mitigate it. Andre (2008) states that understanding information processing will facilitate the mitigation efforts toward confirmation bias that arise during the information search and evaluation. As a result, it is expected to prevent tax consultants from providing inappropriate recommendations.

The information search type shows the confirmation bias level they are experiencing. The consultants who are involved in a decisionfocused search are the consultants with a stronger confirmation bias, while the consultants involved in information-focused searches represent a weaker bias or an unbiased situation. Previous studies such as by Kennedy (1993), Schafer and Schafer (2009) and De Zoort et. al (2006) found that accountability successfully mitigated the bias experienced by professional accountants in searching and evaluating information. Based on the explanations of Ditto and Lopez, 1992; Ditto et al., 2003 and the above empirical findings, Hypothesis 3 (H3) is formulated as follows:

H3: The information search depth moderates the effect of the information search types toward the tax recommendation

Olvera (2012) classified the type of information search into two categories: informationfocused and decision-focuced. Based on that classification, Misra et al., (2018a) predicted and found that tax consultants who receive a tax preferred position explicitly from their clients engaged in an information-focused search, while tax consultants who receive preference statements implicitly will make a decision-focused information search. Consultants who are involved in a decision-focused information search will pay greater attention to any information that supports their client's preferences. This tendency shows that they engage in a confirmatory bias during the information search process. Furthermore, cconsultants who are involved in a biased and shallow information search are predicted to consider information that supports their client's preferences as being the most important. Consequently, they tend to discredit or discount information that is contradictory to the client's preferences, since the main focus of their information search is their client's preference. Therefore, tax recommendations from consultants with a decisionfocused and shallow search will closely approach the facts and support the evidence presented by the client. However, when consultants are engaged in a decision-focused 
and deep search, referring to the accountability demands they face from supervisors, they exert greater cognitive efforts in their information search, to avoid potential errors in the judgment they made. Thus, in providing tax recommendations the consultant will consider the evidence or information in a more comprehensive and balanced manner. As a result, these tax consultants provide a more conservative recommendations than consultants involved in a decisionfocused and shallow information search. This explanation leads to Hypothesis 3a (H3a), as follows:

H3a: When a consultant is involved in a decision-focused search, there will be a large difference in the tax recommendation between the consultant undertaking a shallow search and the consultant conducting a deeper search.

Misra et al., (2018a) also found that tax consultants who received explicit statements about client preferences performed an information-focused search.This type of search can be interpreted as a search for various bits of information during their information search process. Consultants who performed an information-focused search followed by a shallow search should already have sufficient information as the basis for the recommendations they will provide. However, consultants who carry out an information-focused search complement by a deep information search may have obtained a wider variety of information, and more detailed information, during their information search process. According to Olvera (2012), professionals involved in this search condition not only get information with content that supports their judgment, but also show content that reflects their efforts. Due to an unbiased information search and sufficient information being held by the tax professional to make a proper recommendation, Hypotheses 3bis formulated as follows:

H3b: When the consultant is engaged in an information-focused search, there will be a smaller difference in the tax recommendation between the consultant conducting a shallow search and the consultant employing a deeper search.

\section{RESEARCH METHOD}

\section{Research Design}

A controlled laboratory experiment was conducted to test the hypotheses,using a $1 \times 2$ between-subjects design.The independent variable isthe accountability pressure (strong or weak). Given the type of information search which contains confirmation bias,as experienced by the participants during the information search process, this study was able to examine the influence of accountability pressure on information search behavior, and whether such behavior affects tax recommendations. The experiment is conducted using a web-based instrument. Prior to performing the experiment, a focused group discussion and a series of pilot tests were conducted to verify the validity and reliability requirements of the research instrument.

\section{Experimental Task and Procedures}

The task concerns corporate taxation and whether several accounts can be taken as deductions. The task specifically relates to tax research, i. e., collecting and assessing tax evidence in relation to a tax reporting issue. The participants performed the task by providing advice toward the client's fiscal reconciliation draft. The task contains tax issues that are often decided at tax audit findings or are subject to correction by the tax authorities. Cases are developed hypothetically by abstracting the real 
cases and other inputs which are relevant to the purpose of the study. The experimental task of searching for information items is built by studying the tax court cases obtained from the tax court's decision directory. The cases can be accessed through the official website of the Indonesian Supreme Court ${ }^{1}$. Each case is written in similar style to the actual tax court's decree.

The experiment was conducted on an internet-based basis and the research was designed by a computer-assisted randomization, through systems which are built into research instruments. The participants get the access code to log-in to the experimental instrument site. From the main menu on the research instrument, the participants can access assignment memos, client facts, case databases and notebooks. They are allowed to search for information from a database that is available for 30 minutes. During the search period, the participants can review: (1) an assignment memo, (2) an overview of a meeting with clients, (3) client facts and (4) databases containing 14 cases / information. After completing their information search, the participants were asked to report the strength of the recommendations they advised. Then, participants were asked to complete the demographic data and answer the manipulation check questions. Finally, the researcher delivered a debriefing.

\section{Research Variables}

The primarily focus of this research is into accountability pressure, information search depth and tax recommendations. However, since it is necessary to test how the confirmation bias happened, the influence of client preferences toward the information search type were tested first. Client preference is the client's desire

\footnotetext{
${ }^{1}$ Cases can be accessed through

https://putusan.mahkamahagung.go.id/pengadilan/pengad ilan-pajak.
}

regarding their tax reporting position. Misra et al., (2018a) examined the influence of client preference statements on the information search type. They showed that tax consultants who received an implicit client preference exhibit a stronger confirmation bias (engaged in a decision-focused search type). This bias subsequently lead them to provide an aggressive recommendation.

The accountability pressure is the pressure perceived by individuals to fulfill the requirements requested by the source of the accountability (the party to whom they are accountable) for the work assigned to them. Accountability pressure arises when a judgment or decision must be justified to another party who is considered to be important (DeZoort et al., 2006).To manipulate accountability pressure, the participants were provided with a fictituous assignment memo indicating their supervisor's pressure. The participants assigned to the "weak pressure" condition were given a memo containing a request to solve a tax issue without their identity becoming known (anonimity). In contrast, the participants assigned to the "strong pressure" condition were given a memo stressing their supervisor's pressure and requesting the participants' identity and asked for their official feedback. The information search depth is measured by its duration and citation, while the tax recommendation was modified from Cloyd and Spilker (1999). The duration refers to the amount of time spent searching for information, both for information that is consistent and inconsistent with the client's preference, while citation refers to information items cited to prepare the tax recommendation. Cloyd and Spilker (1999) measured the tax recommendation by requesting subjects to take a particular tax position on the client's tax return at the range from -3 to +3 . This study modified that measure by dividing the excess claimed in the deductible 
expenses by the allowed expenses. To deliver the interaction and simple effect tests, the information search type tested in Misra et al., (2018) was included into the research framework (dashed line box in Picture 1). They split the information search into two levels: a decisionfocused search and an information-focused search. Meanwhile,the depth of the information search was classified into a deep search and a shallow search.These level classifications used a median-based split.Furthermore, regarding the fact that some previous research (i.e., Cloyd 1995; Schafer, 2007) had found that knowledge influenced the information's search and evaluation process, this study inserted the knowledge variable into the model as a covariate.

\section{Participants and Manipulation Check}

Libby et al. (2002) suggest that the researcher has to consider the requirements of the experiment to determine the proper participants. Professional tax consultants who work in the Tax Consultants Office (TCO) as well as those who work in the Certified Public Accountants Office (CPAO) and the Accounting Services Office are the subjects for this research. CPA offices is considered as an important part of tax advisory provider because they received a significant amount of revenue from tax services. Data shows that about $20 \%$ to $25 \%$ (with the average is of 23\%) of the total CPAO's revenue come from tax services (Lee, 2015; Big4, 2015).

Participants are recruited by e-mail invitation and by phone. The potential participants' data was acquired from the Indonesian Tax Consultants'Association and the Public Accountants'Company directory. The subjects who are participating in the study should have a minimum of one year's work experience. This requirement was applied to capture the subjects' experience in solving clients' tax issues. Data from the subjects who did not meet this requirement were dropped from the analysis.To ensure a proper control for this experiment, the participants are told to complete the experimental task within an uninterrupted 40-minutes time-frame. Manipulation checks were performed by asking the participants about their experiences during the experiment. Lastly,a debriefing was held for all the committed participants.

\section{Data analysis}

This research operationalizes the information search depth using two distinctive measures, which are its duration and citation. To test the first hypothesis, this study used Multivariate Analysis of Variance (MANCOVA) to compare the dependent measures (i.e information search depth) under an accountability pressure condition by considering the consultants' knowledge as the covariate. To test the second hypothesis, this study conducted a regression analysis to examine the relationship of each search depth measure (duration and item) towards the tax recommendation. The third hypothesis was tested by using three measures for the information search type from Misra et al. (2018a) (rank, time and save) with the information search depth measures (duration and citation) using a median-based split. Rank refers to the amount of weight for consistent-information toward total weight, while time refers to time spent to prepare tax recommendation for consistent information divided by total time consumed. Lastly, save was measured by comparing information saved for consistent information divided by the total information item provided. The test was performed with Analysis of Variance (ANOVA) and SPSS syntax for ANOVA. 


\section{FINDINGS AND DISCUSSION}

\section{Participants and Manipulation Check Result}

The participants in the study are tax professionals employed at the Tax Consultants Office, the Certified Public Accountants Office and the Accounting Services Office. The participants completed an online experimental task. They started by opening the task website and logging-in using a specified username and password. Out of the 172 usernames distributed, there are 122 participants who have ever logged in to the system. From that number, only 87 participants finished the task and had their data recorded into the system. Based on the manipulation check test, five participants failed to give a proper response so their data were eliminated, resulting in 82 usable responses. Out of 82 participants, 45 are male (58.88\%) and the other 37 are female (45.12\%). They have various levels of education, ranging from a diploma degree (two persons) to a Ph.D. degree (three persons). The average working experience of the participants is 76.33 months, or 6.4 years, with the average age being 34.61 years old. Based on their affiliations, 40 participants work in the CPAO (48.78\%), 24 work at the Tax Consultants Office (29.26\%) and 18 were from the Accounting Services Office (21.96\%). It was also found that there was no difference in the subjects' characteristics among the experimental treament (cell). This result suggest that the randomization was effective. Table 1 below shows the result of the manipulation checks:

Table 1.Result of Manipulation Check (Overall)

\begin{tabular}{|c|c|c|c|c|c|}
\hline \multicolumn{6}{|c|}{ Panel A. Client Preference } \\
\hline \multirow{2}{*}{\multicolumn{6}{|c|}{$\begin{array}{l}\text { Categorical Manipulation Checks } \\
\text { Client Preference }\end{array}$}} \\
\hline & & & & & \\
\hline & & \multicolumn{2}{|c|}{ Implicit $(\mathrm{N}=45)$} & \multicolumn{2}{|c|}{ Explicit $(\mathrm{N}=42)$} \\
\hline Number of & orrect & \multicolumn{2}{|l|}{43} & \multicolumn{2}{|c|}{39} \\
\hline \multicolumn{6}{|c|}{ Responses } \\
\hline Percentage & f Correct & \multirow{2}{*}{\multicolumn{2}{|c|}{95.55}} & \multirow{2}{*}{\multicolumn{2}{|c|}{92.85}} \\
\hline \multirow{3}{*}{\multicolumn{6}{|c|}{ Scale-based Manipulation Checks }} \\
\hline & & & & & \\
\hline \multicolumn{5}{|c|}{ Client Preference } & \\
\hline & Implicit (N=43) & $\begin{array}{l}\text { Explicit } \\
(\mathrm{N}=39)\end{array}$ & df & $\mathbf{T}$ & Sig \\
\hline Mean (DS) & $2.53(0.847)$ & $3.92(0.823)$ & 80 & 7.560 & 0.000 \\
\hline \multicolumn{6}{|c|}{ Panel B. Accountability Pressure } \\
\hline \multirow{2}{*}{\multicolumn{6}{|c|}{$\begin{array}{c}\text { Categorical Manipulation Checks } \\
\text { Accountability Pressure }\end{array}$}} \\
\hline \multicolumn{5}{|c|}{ Accountability Pressure } & \\
\hline \multicolumn{4}{|c|}{ Strong $(N=44)$} & \multicolumn{2}{|c|}{ Weak $(N=43)$} \\
\hline \multirow{2}{*}{\multicolumn{2}{|c|}{$\begin{array}{l}\text { Number of Correct Respon } \\
\text { Percentage of Correct Respon }\end{array}$}} & \multicolumn{2}{|l|}{41} & \multicolumn{2}{|c|}{41} \\
\hline & & \multicolumn{2}{|l|}{93.18} & \multicolumn{2}{|c|}{95.34} \\
\hline \multirow{2}{*}{\multicolumn{6}{|c|}{$\begin{array}{c}\text { Scale-based Manipulation Checks } \\
\text { Accountability Pressure }\end{array}$}} \\
\hline & & & & & \\
\hline & Strong $(N=44)$ & Weak $(\mathrm{N}=39)$ & df & $\mathbf{T}$ & Sig \\
\hline Mean(DS) & 4.39 (0.145) & $2.64(0.123)$ & 80 & 8.734 & 0.000 \\
\hline
\end{tabular}




\section{Statistics Descriptive and Result of Hypothesis Testing}

Hypothesis 1 aims to examine the effects of accountability pressure on the depth of the information search. The information search depth is measured by the amount of time spent to search for and evaluate the information (duration) and the amount of information cited as a reference in the subsequent tax recommendation (citation). In addition to the independent variables, the testing of Hypothesis 1involves knowledge as the covariate in the model. The MANOVA assumptions test for Hypothesis 1 shows support for all the required assumptions. The participants' responses are described in Table 2 below.

MANOVA results show a significant multivariate primary effect (Pillai's Trace $=0.310, \mathrm{~F}=$ 17.779 , $p$-value $=0.000$ ). The MANOVA model with the aggressiveness of the tax recommendation as its dependent variable is presented in the following Table 3.
From Table 2, it can be seen that the consultants who were under weak accountability pressure spent, on average 426.65 seconds searching and studying the available information, while the consultants under strong accountability pressure spent an average of 615.37 seconds. From the MANOVA model, as presented in Table 3 , the difference (the main effect of accountability pressure) is statistically significant $(F=10.347 ; p=0.002)$. Furthermore, the descriptive statistics of the citation reflecting the amount of information cited as a reference in the making of the recommendation shows consistent results with the duration measure. Table 2 shows that consultants who worked under weak accountability pressure cited 7.503 information items in average, while consultants under strong accountability pressure averagely cited for 9,960 information items. As can be seen in Table 3, the difference (the main effect of accountability pressure) is statistically significant $(\mathrm{F}=25.627 ;$-value $=0.000)$. These results indicate support for Hypothesis 1 for the

Table 2.Mean and Deviation Standard of the Information Search Depth

\begin{tabular}{cccccc}
\hline & $\begin{array}{c}\text { Accountable } \\
\text { Pressure }\end{array}$ & Mean & $\begin{array}{c}\text { Standard } \\
\text { Deviation }\end{array}$ & Participants & $\begin{array}{c}\text { Marginal } \\
\text { Mean }\end{array}$ \\
\hline Duration & 0 & 427.59 & 230.878 & 41 & 426.65 \\
& 1 & 614.44 & 292.285 & 41 & 615.37 \\
\hline Citation & Total & 521.01 & 278.114 & 82 & \\
& 0 & 7.51 & 1.846 & 41 & 7.503 \\
& 1 & 9.95 & 2.469 & 41 & 9.960 \\
\hline
\end{tabular}

Table 3. Between-Subject Effect of Information Search Depth

\begin{tabular}{llrrrc}
\hline \multicolumn{1}{c}{ Source } & Account Pressure & Df & Mean Square & \multicolumn{1}{c}{ F } & Sig. \\
\hline Intercept & Duration & 1 & 861654.593 & 12.291 & 0.001 \\
& Citation & 1 & 264.901 & 55.202 & 0.000 \\
Knowledge & Duration & 1 & 11017.500 & 0.157 & 0.693 \\
\multirow{2}{*}{ Account Pressure } & Citation & 1 & 1.045 & 0.218 & 0.642 \\
& Duration & 1 & 725424.670 & 10.347 & 0.002 \\
& Citation & 1 & 122.979 & 25.627 & 0.000 \\
\hline
\end{tabular}


citation measure. Based on the descriptive and statistical descriptions above, it can be concluded that accountability pressure significantly affects the information search depth after controlling for the participant's knowledge. These findings indicate support for Hypothesis 1 (H1) that predicted consultant staff who received strong accountability pressure will spend more time and save more information items rather than tax consultants who work underweak accountability pressure. Hypothesis 2 predicts the effect of the depth of the information search on tax consultants' recommendations. Consultants who performed a shallow search will provide more aggressive tax recommendations to clients than consultants who performed a deep search. This prediction indicates a negative relationship between the information search depth and the aggressiveness level of the suggested tax recommendation. Considering the potential of multicollinearity between the two measures (duration and citation), then there will be two regression tests. The results of a simple regression test are presented in Table 4 below.

As can be seen from Table 4, both the measures for the information search depth (duration and citation) significantly influence the tax recommendation. The duration measure shows a t-stat of $-3.033(\mathrm{p}=0.003)$, and the citation measure shows a t-stat of-3.873 ( $\mathrm{p}=$ 0.000 ). Table 4 also shows that there is a negative relationship between these two measures for the search depth and the tax recommendations given. These findings indicate support for Hypothesis 2 (H2) that predicts a longer search duration and greater number of items cited by staff during the information search process are negatively related to the subsequent tax recommendation

Hypothesis 3 predicts that the information search depth moderates the effect of the information search types on the tax recommendation prepared by tax consultants. There are six combinations of interaction between the three measures for the information search types (rank, time and save) in Misra et al., (2018) with two measures for the information search depth (duration and citation), that are: rank and duration, time and duration, save and duration, rank and citation, time and citation and save and citation. The conclusion of the ANOVA test results are as shown in Table 5.

Based on the data presented in Table 5, it can be concluded that of the six forms of interaction, there are two combinations that show a significant effect from their interaction (ranking*citation and time*citation). Meanwhile, two combinations showed marginal significant effects (save*duration and save*citation) and the other two interactions were insignificant. This finding indicates partial support for Hypothesis 3.

Table 4. Simple Regression Results (H2)

\begin{tabular}{|c|c|c|c|c|c|c|}
\hline & \multicolumn{3}{|c|}{ Duration } & \multicolumn{3}{|c|}{ Citation } \\
\hline & $\begin{array}{c}\text { Standardized } \\
\text { Beta }\end{array}$ & $\begin{array}{l}\text { t-stat } \\
\text { value }\end{array}$ & $\begin{array}{c}\text { one-tailed } \\
\text { p-value }\end{array}$ & $\begin{array}{c}\text { Standardized } \\
\text { Beta }\end{array}$ & $\begin{array}{l}\text { t-stat } \\
\text { value }\end{array}$ & $\begin{array}{c}\text { one-tailed } \\
\text { p-value }\end{array}$ \\
\hline Intercept & & 11.519 & 0.000 & & 9.034 & 0.000 \\
\hline Duration & -0.321 & -3.033 & 0.003 & & & \\
\hline Citation & & & & -0.397 & -3.873 & 0.000 \\
\hline $\mathrm{R} 2$ & & 0.103 & & & 0.158 & \\
\hline
\end{tabular}


Table 5.Summary of Anova Test for Interaction Effect between Measures

\begin{tabular}{clccl}
\hline No & Variable Combination & Score F & Score-p & \multicolumn{1}{c}{ Conclusion } \\
\hline 1. & Rank*Duration & 0.068 & 0.794 & Not Significant \\
2. & Time*Duration & 1.218 & 0.273 & Not Significant \\
3. & Save*Duration & 3.363 & $0.071^{*}$ & Marginally Significant \\
4. & Rank*Citation & 6.445 & $0.013^{* *}$ & Significant \\
5. & Time*Citation & 8.435 & $0.005^{* *}$ & Significant \\
6. & Save*Citation & 2.839 & $0.096^{*}$ & Marginally Significant \\
\hline Description: ${ }^{* *}$ sig at $\mathrm{p}<0.05 ; * \operatorname{sig}$ at $\mathrm{p}<0.1$ & &
\end{tabular}

Since the results of Hypothesis3 indicate the presence of significant interaction effects on two independent variable combinations, testing for hypotheses H3a and H3b can be continued. Testing for H3a and H3b aims to see whether there are differences in the tax recommendations provided between consultants performing a shallow search and those doing a deep search, when the consultants are engaged in one type of search of information (decision-focused or information-focused). Descriptive statistics of the rank and citation measure interaction tests are presented as follows Table 6 .

As can be seen from Table 6, there is a difference in the tax recommendations between tax consultants who conduct a shallow search and a deep search in a decision-focused search condition ( $\mathrm{F}=26.267 ; p=0.000)$. These results indicate support for H3a. From Table 6,the result of the simple effect test in an informationfocused condition can also be seen. It shows that there is no difference in the tax recommendations between consultants conducting a shallow search or a deep search $(\mathrm{F}=2.356$; $p=$ 0.129). This result shows support for Hypothesis 3b.

Meanwhile, descriptive statistics for the interaction of time (search type) and citation (search depth) are presented as follows Table 7.

As can be seen from Table 7, there are differences in the tax recommendations between tax consultants who conduct a shallow search and those who perform a deep search in a decision-focused search condition ( $F=31.660$; $p$ $=0.000$ ). This result suggests support for H3a. Table 7 also provides the result of the simple effect test for the information-focused condition. It shows that there is no significant difference in the tax recomendation between the consultants with a shallow search and a deep $\operatorname{search}(\mathrm{F}=$ 2.308; $\mathrm{p}=0.133$ ). This result indicates support for Hypothesis $3 \mathrm{~b}$.

Table 6.Univarate test for rank*citation

\begin{tabular}{llccccc}
\hline & Rank & Sum of Squares & df & Mean Square & F & Sig. \\
\hline 0 & Contrast & $1 ., 023$ & 1 & 1.023 & 26.267 & 0.000 \\
& Error & $3 ., 037$ & 78 & 0.039 & & \\
1 & Contrast & 0.092 & 1 & 0.092 & 2.356 & 0.129 \\
& Error & $3 ., 037$ & 78 & 0.039 & & \\
\hline
\end{tabular}

Table 7. Univarate test for time*citation

\begin{tabular}{llccccc}
\hline & Time & Sum of Squares & Df & Mean Square & F & Sig. \\
\hline 0 & Contrast & 1.152 & 1 & 1.152 & 31.660 & 0.000 \\
& Error & 2.838 & 78 & 0.036 & & \\
\multirow{2}{*}{1} & Contrast & 0.084 & 1 & 0.084 & 2.308 & 0.133 \\
& Error & 2,838 & 78 & 0.036 & & \\
\hline
\end{tabular}




\section{DISCUSSION}

Among the advisory service offered by accounting firm, Ttax consulting services represents a significant component and requires high quality advice (Andre, 2008). Given the uncertainty faced by a client's tax condition and position, the tax professional must conduct research and should have the ability to localize the relevant evidence, or authorities, in support of the judgments made (Marshall et al., 1992). Rose and Wolfe (2000) suggest that the potential overload of information (information overload) is one of the characteristics of the tax professional's environment. Considering the massive number of cases on certain issues, and the time constraints, the research consultant should be selective in choosing authoritative evidence to be read and used for consideration in their judgment making (Wheeler and Arunachalam, 2008). Therefore, tax professionals need to gain a balanced view of the evidence and information, and do not focus preferentially on one condition that supports the preferred tax position, by ignoring the other. However, previous research (such as Cloyd and Spilker, 1999; Kadous et al., 2008; Wheeler and Arunachalam, 2008) showed that tax professionals may be engaged in a confirmation bias during their information search and judgment process. It means they placed more emphasis on information which is consistent with their client's preference and discounted contrary information. Considering the risk potential due to the confirmation bias being exhibited, such bias and/or its effect should be mitigated.

The findings of this study, as described in the previous section, show that accountability pressure from supervisors influences the information search depth, after controlling for the effects of the knowledge factor. These findings indicate that the accountability pressures provide an effective mechanism to induce participants' cognitive efforts in their information search process. Participants in a high accountability pressure condition (official feedback) search the information to a greater depth and pay more attention to information in a more detailed and broader way than participants in weak accountability conditions (anonymity). This result suggest that tax consultants are aware of the accountability pressures they face. Moreover, this awareness leads them to obtain approval and/or avoid sanctions, and exert more cognitive efforts. The result is consistent with the expectation that the search behavior (i.e., information search depth) of those in the high accountability pressure condition and those in the weak accountability pressure do differ. This finding is consistent with the social contingency model proposed by Tetlock (1992) and the selfattention model by Carver (1979), where accountability pressure motivates an individual into a greater cognitive effort. This finding was confirmed by some previous research (e.g., DeZoort et al., 2006; Raush and Brauneis, 2015) that found accountable subjects employ more cognitive effort than non-accountable subjects.

Furthermore, the results indicate that the information search depth is negatively related to the tax recommendation. That is, a tax professional who performed a deep information search (shown by more time spent searching for information and citing more information when preparing his/her recommendations) provide more conservative (less aggressive) tax recommendations than those who performed a shallow search. The result indicated that a tax recommendation is strongly influenced by the depth of the information search. Tax consultants who performed a deep search are assumed to have already obtained sufficient and more balanced information. Furthermore, this condition leads them to consider all types of information during the preparation of their recommendations, which 
results in more conservative advice.On the other hand, a tax consultant who performes a shallow search tends to follow the client-preferred tax position. This findings contradicts Olvera (2012), who found that the information search depth does not influence the documentation's quality. She found that there is no difference in auditors' documentation quality between participants who perform a deep search and those who conduct a shallow search.

Andre (2008) states that an understanding of the processing of the information will facilitate efforts to mitigate the confirmatory bias that arises during the information search and evaluation. Previous studies such as Kennedy (1993), Schafer and Schafer (2009) and DeZoort et al. (2006) found that accountability may mitigate bias in an auditor's considerations, in various contexts of audit work. This study confirms these results.

The results of Hypothesis 3's testing show that two of the six forms of interaction between the search type measures and the search depth measures interact significantly. These findings indicate that the information search depth moderates the relationship between information search types and tax recommendations. This result can be interpreted as a signal of accountability's effectiveness in mitigating the confirmation bias. This finding implies a higher level of accountability will encourage a more complex and careful analysis of the available information.

Moreover, the results of the simple effect test of the two interactions (citation * rank and citation *time) show consistent results with the predictions (H3a and $\mathrm{H} 3 \mathrm{~b}$ ). As predicted, the most aggressive tax recommendation occurs when the consultant is involved in a decisionfocused and shallow search. Meanwhile, consultants involved in an information-focused search with a shallow search provide recommendations that are not much different from consultants with a decision-focused search who conduct a deep search. The most conservative recommendations are shown by consultants with an information-focused and deep search. When the search type is informationfocused, there is no significant difference between the deep and shallow searches. This finding implies that the consultant can perform an efficient search by not for feiting the quality of the given recommendations, when the consultant is not engaged in a biased search. In addition, though a tax consultant was engaged in a biased search, accountability pressure may play an important role to mitigate it through a deep information search. These findings suggest that internal accountability pressures, which lead tax consultants to perform a deep search is effective inmitigating the confirmation bias that occurs during the information search processes.

Considering that the information search has long been recognized as an important component in the professional tasks of tax consultants, this study would like to reaffirm the importance of knowing how a client preferences their delivered, and how tax professionals respond their client's preference request. Concern for that condition will help tax professionals to prapare an optimal tax recommendation.

\section{CONCLUSIONS, IMPLICATIONS AND LIMITATIONS}

The study found accountability pressure influences tax consultants' information search behavior. These findings support the explanation of the social contingency model from Lerner and Tetlock (1992). The results of this study are consistent with the findings of Cloyd (1997), DeZoort et al., (2006), and Raush and Brauneis (2015). The information search depth relates negatively to the given tax recommendations. A tax consultant who spends more time searching 
for information and who cites more items can be assumed to aquire more relevant and balanced information related to their client's tax issue. Consequently, they make a more careful judgment when preparing their tax recommendation. As a result, they suggest a more conservative recommendation. In other word, tax consultants undertaking a deep search provide less aggressive recommendations than consultants involved in a shallow search.

Moreover, it was found that the information search depth moderated the relationship between the information search type and the tax recommendations provided. The results of Hypothesis 3 (H3) indicate that two of the six interactions have an effect. This finding implies that the information search depth, as a consequence of accountability pressure, can mitigate the negative effects of confirmation bias. Finally, this study shows that when consultants are involved in a decision-focused information search, the information search depth determines the tax recommendation. On the other hand, the search depth does not significantly influence tax recommendations when participants engage in an information-focused search. This finding implies that consultants can search more effectively and efficiently as long as they are not engaged in a confirmation bias when searching for information. The effectiveness of the evaluation of the information search is important to the consultant,due to the nature of their timelimited work. This study's findings suggest that internal accountability pressure, stemming from the supervisors, is still effective as a mechanism to mitigate the confirmation bias experienced by tax professionals during their information search and judgment making.

There are several limitations that can be identified from this study. First, the recommendation process is not entirely self-employed, but involves a comprehensive group process, so it is possible that the group's dynamics may eliminate or even reinforce an individual's confirmation bias. Therefore, future research needs to consider the group process in examining the potential for confirmation bias in the search for information and making tax recommendations. Second, the participants searched for information from a limited database to resolve their clients' tax issues. In practice, tax consultants may have almost unlimited access to information. Third, the study did not consider the effects of task characteristics (such as task structure and complexity) on the tax professionals' job performance. O'Donnnel et al. (2005) state that task complexity is an important factor in the tax professionals' work. Tax professionals routinely relate to the complexity of a task when making tax recommendations for their clients (Shields et al., 1995). Future research needs to investigate and /or control the task characteristics that may affect the individual's performance.

\section{REFERENCES}

American Institute of Certified Public Accountants (AlCPA). (1995). A1CPA Professional Standards and Code of Professional Conduct. New York. NY: AICPA.

American Institute of Certified Public Accountants (AICPA). (2008). AICPA Professional Standards. New York, NY: AICPA.

Andre, Sean. (2008). Confirmatory behavior in tax: Exploring how advisors search for and evaluate information. Diakses dari ssrn.com dengan tautan http://ssrn.com/abstract $=1093370$

Cloyd, C. (1997). Performance in tax research tasks: the joint effects of knowledge and accountability. The AccountingReview, 72: 111-132.

Cloyd, C. B., \& B. C. Spilker. (1999). The influence of client preferences on tax professionals' search for judicial precedents, 
subsequent judgments and recommendations. The Accounting Review 74 (3): 299322.

DeZoort, T., P.Harrison \& M. Taylor. (2006). Accountability and auditors' materiality judgments: The effects of differential pressure strength on conservatism, variability, and effort. Accounting, Organization and Society 31: 373-390

Ditto, P. H. \& D. F Lopez. (1992). Motivated skepticism: Use of differential decision criteria for preferred and non-preferred conclusions. Journal of Personality and Social Psychology 63: 568-584

Ditto, P. H.,G. D. Munro., A. M. Apanovitch., J. A. Scepansky \&L. K. Lockhart. (2003). Spontaneous skepticism: The interplay of motivation and expectation in response to favorable and unfavorable medical diagnoses. Personality and Social Psychology Bulletin 29: 1120-1132.

Gibbins, M., \& J.D. Newton. (1994). An empirical exploration of complex accountability in public accounting. Journal of Accounting Research 32: 165-186.

Hansen, V. J \& R. A. White. (2012). An investigation of the impact of tax preparer penalty provision on tax payers aggresiveness. The Journal of American Taxation Association 34(1): 137-165.

Kadous, K., A. Magro \& B. Spilker. (2008). Do effects of client preference on accounting professionals' information search persist with high practice risk? The Accounting Review 83 (1): 133-156.

Kennedy, J. (1993). Debiasing audit judgment with accountability: A framework and experimental results. Journal of Accounting Research 31 (Autumn): 231-245.

Koch, C \& S. E. Salterio. (2015). Effects of client pressure and audit firm management control systems on auditor judgments. Working Paper.

Kunda, Z. (1990). The case for motivated reasoning. Psychological Bulletin 108 (3): 480-498.
Lee, S.Y. (2015). Factors affecting audit revenues. Advanced Science and Technology Letters 102: 6-9

Lerner, J. S. \&P. E. Tetlock. (1999). Accounting for the effects of accountability. Psychological Bulletin 125 (2), 255-275.

Libby, R., R. Bloomfield, and M. W. Nelson. (2002). Experimental research in financial accounting. Accounting, Organizations and Society 27: 775-811.

Misra, Fauzan., S. Sugiri., E. Suwardi \& E. Nahartyo. (2018). Information search behavior and tax consultants' recommendation: Experimental examination on the role of social norms. Working Paper: Universitas Gadjah Mada.

Nickerson, R. S. (1998). Confirmation bias: A ubiquitous phenomenon in many guises. Review of General Psychology 2 (2): 175220

Nisbett, R., \& L. Ross. (1980). Human inference: Strategies and shortcomings of social judgment. Prentice Hall.

Olvera, R. M. (2012). Auditors' information search and documentation: Does knowledge of the client preference or PCAOB accountability pressure matter? University of North Texas: Dissertation.

Raush, A., \& A. Brauneis. (2015). It's about how the task is set: the inclusion exclusion effect and accountability in preprocessing management information. Central European Journal of Operations Research 23: 313344

Republik Indonesia. (2014). PMK No. 111/PMK.03/2014 tentang Konsultan Pajak

Rufus, R. J.\& Sennetti, J. T. (2007). Jurors' evaluations of decision-aid use in a tax malpractice setting. Paper read at 2007 ABO Research Conference, Philadelphia.

Schafer, B.A \& J. K. Schafer. (2009). Justification and self-review: mitigating irrelevant effects in fraud judgments, in Vicky Arnold (ed.) Advances in Accounting Behavioral Research (Advances in Accounting Behavioral Research, Volume 
12) Emerald Group Publishing Limited: 41 $-59$

Schlenker, B. \& M. Leary. (1982). Social anxiety and self-presentation: a conceptualization and model. Psychological Bulletin, 92(3), 641-669.

Simone, L.D., R. C. Sansing \& J. K. Seidman. (2008). When are enhanced relationship tax compliance program mutually beneficial? The Accounting Review 88 (6): 1971-1991.

Simonson, I \& B. M. Staw.(1992). De-escalation strategy: a comparison of techniques for reducing commitment to losing course of action. Journal of Applied Psychology 77: 419-426.

Stephenson, T. (2010). Measuring tax payers's motivation to hire tax preparers: the development of a for-construct scale. Advances in Taxation 19: 95-121

Tetlock, P. E. (1985). Accountability: The neglected social context of judgment and choice. Research in Organization Behavior 7: 297-332.
Tetlock, P.E, L. Skitka, \& R. Boettger. (1989). Social and cognitive strategies for coping with accountability: Conformity, complexity, and bolstering. Journal of Personality and Social Psychology 57 (4): 632-640.

Tetlock, P. (1992). The impact of accountability on judgment and choice: toward a social contingency model. Advances in Experimental Social Psychology, 25, 331-376.

Turner, C. W. (2001). Accountability demands and the auditors' evidence search strategy: The influence of reviewer preferences and the nature of the response (belief vs. action). Journal of Accounting Research 39 (3): 683-706.

Wason, P. C. (1960). On the failure to eliminate hypotheses in a conceptual task. Quarterly Journal of Experimental Psychology 12: 129-140.

Wheeler, P. R.\& Arunachalam, V. (2008). The effects of decision aid design on the information search strategies and confirmation bias of tax professionals. Behavioral Research in Accounting, 20(1): 131-145. 